\title{
Preparation and study of superficially coloured lead glass
}

\author{
C. GIL \\ Fundación Centro Nacional del Vidrio. Po Pocillo, 1, 40100 La Granja de San Ildefonso, \\ (Segovia), Spain
}

M. A. VILLEGAS*

Centro Nacional de Investigaciones Metalúrgicas, CSIC, Avda. Gregorio del Amo, 8. 28040, Madrid, Spain

E-mail: mavillegas@cenim.csic.es

J. M. FERNÁNDEZ NAVARRO

Instituto de Óptica, CSIC, C. Serrano, 121, 28006, Madrid, Spain

Published online: 8 September 2005

\begin{abstract}
Superficially coloured lead crystal glass was obtained by ion-exchange with silver. Both red and yellow ruby colouring were achieved by the presence of small silver particles (colloids) dispersed into the ion-exchanged glass surface. Direct silver ion-exchange of the glass yielded yellow colouring (optical absorption around $410 \mathrm{~nm}$ ). Silver ion-exchange of lead glass previously doped with a reducing agent (i.e., arsenic oxide) yielded red colouring, (optical absorption around $600 \mathrm{~nm}$ ), which indicated special arrangement for silver colloids in the exchanged layer. Parameters that influenced the ion-exchange process, such as temperature, exchange time, dopant percentage and composition of molten salts bath (where the ion-exchange took place), were examined in order to select the best conditions to obtain colours with decorative interest. Optical absorption spectroscopy and scanning electron microscopy were used to determine colour coordinates and silver diffusion profiles, respectively. Direct observation of the silver colloids were performed by means of transmission electron microscopy. Finally, once the optimum process parameters were tested, an intense red ruby colouring (more than $98 \%$ colour purity) was reached. Industrial application of this process arises positively, since some handicaps from traditional bulk colouring could be avoided. (c) 2005 Springer Science + Business Media, Inc.
\end{abstract}

\section{Introduction}

Ion-exchange process is a route to attain chemical tempering in glasses. This method pursue is to create compression stresses that can mechanically reinforce the glasses [1]. Superficial compression generated is due to local modification of the glass composition, which is a consequence of the exchange of alkaline ions from the glass by other ions from the molten salts bath, in which the substrate to be exchanged is dipped on.

When the exchange ion has redox properties, as is the present case with silver, $\mathrm{Ag}^{+}$-ions once diffused into the glass can be reduced by the glass thermoreducing components [2-4]. By further aggregation, small metallic colloids can be formed. If no reducing agents exist in the glass, the result of ion-exchange is a colourless glass, since silver remains as ions or isolated (nonaggregated) atoms [5]. Subsequent thermal treatment of silver exchanged glass deals with the reduction of
$\mathrm{Ag}^{+}$-ions in the glass surface and the diffusion of silver towards deeper glass layers, forming metallic silver colloids that stain the glass surface. Generally, silver particles are dispersed as spherical colloids or monocrystals that appear isolated from each other [6]. Silver particle diameter usually increases as penetration depth in the exchanged layer is higher. Silver colloids grow in the glass surface with the thermal treatment up to few nanometers $(\approx 10 \mathrm{~nm})$.

The longer the heat-treatment at which silver exchanged glasses are submitted, the thicker are the exchanged layers formed. The colour obtained in silver exchanged conventional glasses is yellow-amber [7].

When glasses containing small percentages (1$5 \mathrm{wt} \%$ ) of arsenic oxide are silver exchanged, a red colouring appears, which indicates that a different behaviour or response occurred related to that of undoped glasses. The studies about this red type glasses [8] 
demonstrated that crystalline spherical silver particles exist. Size distribution of silver colloids diameter is a Gaussian form and shows a main particle size almost independent of penetration depth. Both transmission electron microscopy observations and absorption spectra confirm that near the glass surface silver colloids with different size and shape coexist, while in deeper layers colloid concentration and aggregation degree decrease. Hence, red colouring must be attributed to both different spatial distributions and different aggregation kinds of silver colloids, in particular near the glass surface where silver concentration is the highest in the exchanged layer. In this case, dominant wavelength deduced from the optical absorption spectra of stained glasses, is higher than $600 \mathrm{~nm}$ (red colouring) [9].

In the present work the objective was to attain superficially ruby coloured lead crystal glass by means of ion-exchange. The choice of this method was made in order to arrange a more controllable and reliable experimental process (redox conditions and temperature) in comparison with traditional bulk colouring methods for obtaining red and yellow ruby colouring in lead crystal glass. Another important advantage is the economic savings that could be derived from the ion-exchange colouring process. Moreover, decorative and functional purposes highlight the interest of the procedure here studied.

\section{Experimental}

Two experimental arrangements were made with the aim to obtain yellow and red coloured lead crystal glass, since both colours are difficult to attain by traditional methods (for instance, bulk conventional colouring or superficially by an overlaying procedure or plaqué method). The two proposed routes were as follows:
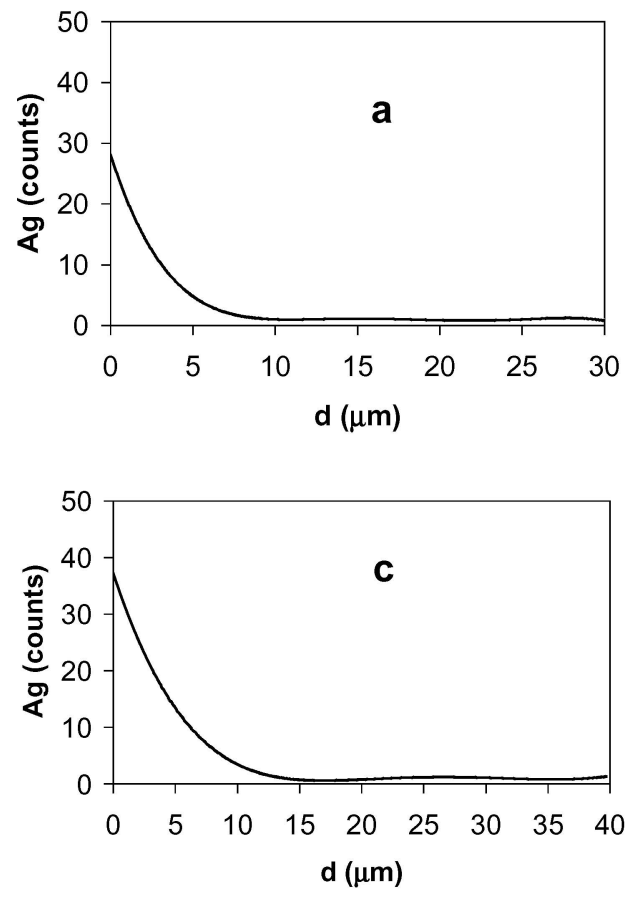

TABLE I Composition (wt $\%$ ) of the lead crystal glass used as a substrate for ion-exchange

\begin{tabular}{lllllll}
\hline \multicolumn{7}{c}{ Oxides $(\mathrm{wt} \%)$} \\
$\mathrm{SiO}_{2}$ & $\mathrm{PbO}$ & $\mathrm{K}_{2} \mathrm{O}$ & $\mathrm{Na}_{2} \mathrm{O}$ & $\mathrm{BaO}$ & $\mathrm{B}_{2} \mathrm{O}_{3}$ & Other \\
58.1 & 24.0 & 10.6 & 3.6 & 1.9 & 0.9 & 0.9 \\
\hline
\end{tabular}

Set 1. Silver ion-exchange upon undoped lead crystal glass in order to obtain yellow ruby colouring.

Set 2. Silver ion-exchange upon lead crystal glass doped with arsenic oxide (1-5 wt $\%$ added) as a reducing agent, which promotes red ruby colouring.

In all cases the starting material used was a colourless lead crystal glass [10] manufactured by the Fundación Centro Nacional del Vidrio - Real Fábrica de Cristales at La Granja de San Ildefonso, Spain (Table I). Samples from the resulting glasses, undoped and arsenic oxide doped, $2 \mathrm{~mm}$ thickness were polished by both sides.

In Set 1 the silver behaviour during the ion-exchange process was checked with undoped samples for a fixed salt bath composition $\left(2 \mathrm{AgNO}_{3} \cdot 98 \mathrm{NaNO}_{3}, \mathrm{~mol} \%\right)$, in order to diminish the variables affecting the procedure. In turn, time and temperature of ion-exchange, as well as the time and temperature for further developing heat-treatment, were changed for this test set. Prior to selecting the time and temperature ranges for ion-exchange and thermal treatment, the linear thermal expansion curve of the lead glass substrate was recorded with a Netzsch dilatometer, model 402 EP. From the expansion curve obtained, glass transition temperature and linear expansion coefficient were calculated $\left(T_{\mathrm{g}}=449.6^{\circ} \mathrm{C}\right.$ and $\alpha=10.04 \times 10^{-6} \mathrm{~K}^{-1}$, respectively). These results allowed the selection of a temperature range for ion-exchange, which was 350$500^{\circ} \mathrm{C}$. Dipping time of samples into the molten salts
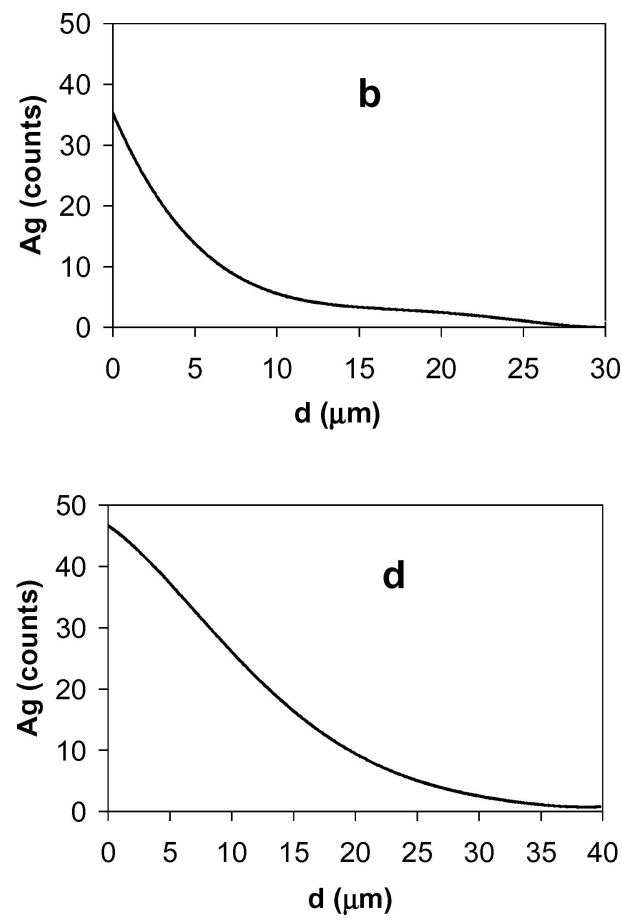

Figure 1 Silver diffusion depth profiles in lead glass ion-exchanged with $\mathrm{Ag}^{+}$-ions for $30 \mathrm{~min}$, (a) at $350^{\circ} \mathrm{C},(\mathrm{b})$ at $400^{\circ} \mathrm{C},(\mathrm{c})$ at $450^{\circ} \mathrm{C}$, and (d) at $500^{\circ} \mathrm{C}$. 

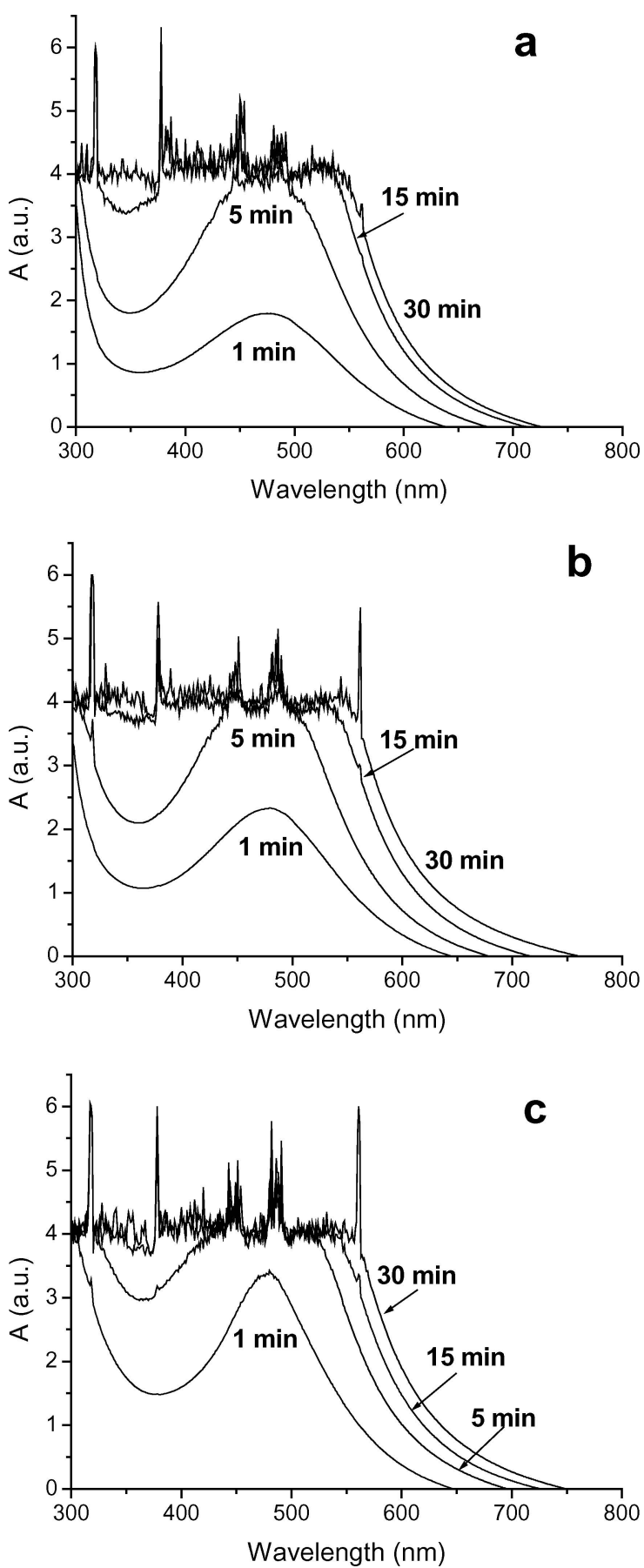

Figure 2 Optical absorption spectra of samples doped with $3 \mathrm{wt} \%$ arsenic oxide, ion-exchanged at $500^{\circ} \mathrm{C}$ for different times into a bath with, (a) $1 \mathrm{~mol} \% \mathrm{AgNO}_{3}$, (b) $2 \mathrm{~mol} \% \mathrm{AgNO}_{3}$, and (c) $4 \mathrm{~mol} \% \mathrm{AgNO}_{3}$.

bath varied between 1 and $120 \mathrm{~min}$. A further heattreatment was performed with ion-exchanged samples in order to grow silver colloids, which favoured a more intense yellow colouring. Heat-treatment temperatures tested were the same or higher than that for ion-exchange, for lengths of time in the 30-120 min range. Silver penetration depth profiles were performed by scanning electron microscopy and energy dispersive X-ray microanalysis with a Philips XL30 equipment.

In Set 2, where red ruby colouring was the final objective, lead crystal glass was doped with 1-5 wt $\%$ of arsenic oxide by melting, using an electric furnace. In this case, composition of the molten salts bath
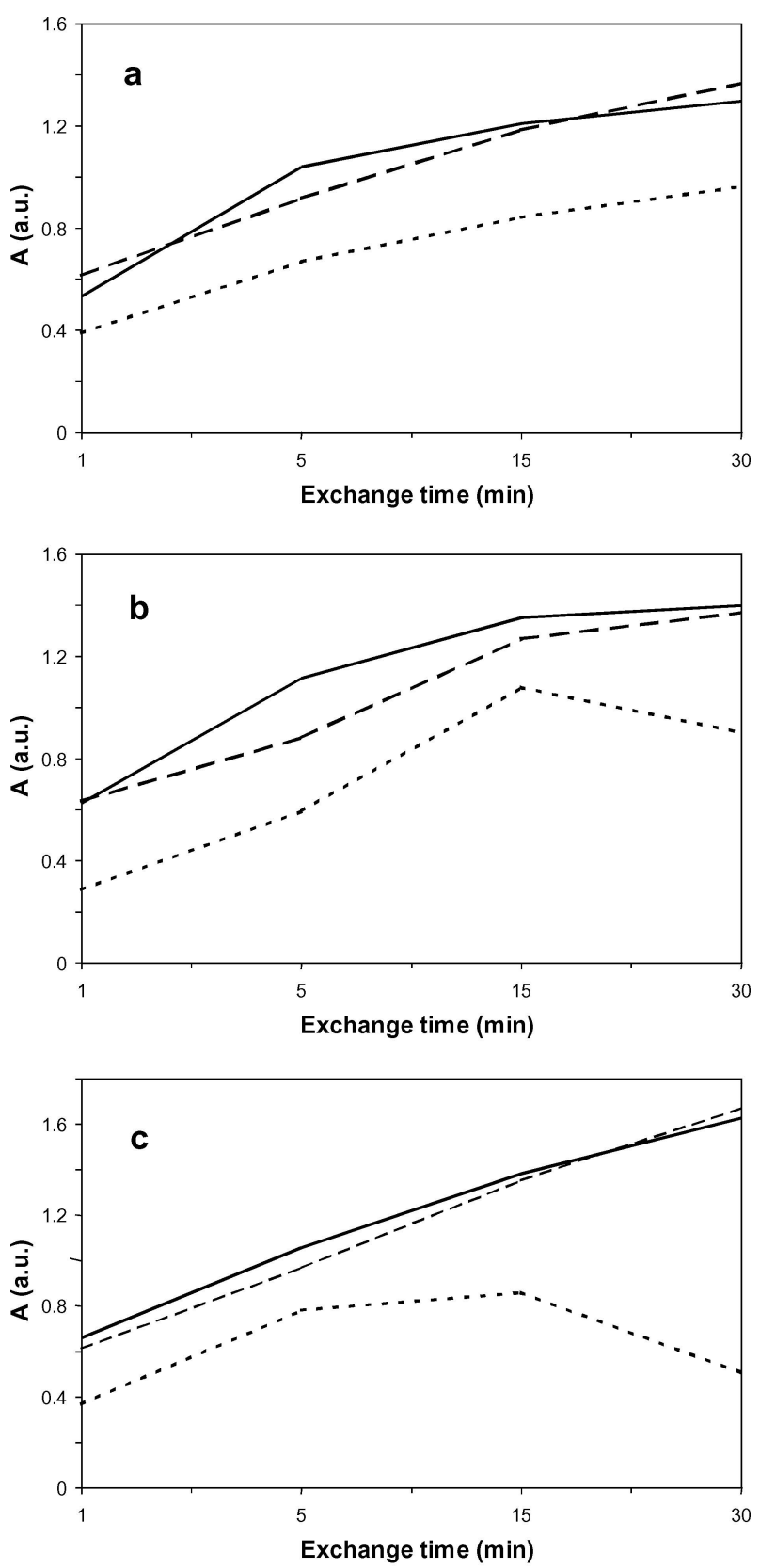

Figure 3 Evolution of optical absorption intensities (measured at $630 \mathrm{~nm}$ ) versus treatment time for samples ion-exchanged into a salts bath with, (a) $1 \mathrm{~mol} \% \mathrm{AgNO}_{3}$, (b) $2 \mathrm{~mol} \% \mathrm{AgNO}_{3}$ and (c) $4 \mathrm{~mol} \%$ $\mathrm{AgNO}_{3}$. Solid line: $5 \mathrm{wt} \% \mathrm{As}_{2} \mathrm{O}_{5}$; dashed line: $3 \mathrm{wt} \% \mathrm{As}_{2} \mathrm{O}_{5}$ and dotted line: $1 \mathrm{wt} \% \mathrm{As}_{2} \mathrm{O}_{5}$.

was $x \mathrm{AgNO}_{3} \cdot(100-x) \mathrm{NaNO}_{3}(x=1,2$, and 4 mol\%). Exchange temperature ranged between 350 and $500^{\circ} \mathrm{C}$; while dipping time of samples into the salts bath varied from 1 to $60 \mathrm{~min}$. For this sample set further thermal treatment was unnecessary, since arsenic oxide behaved as a reducing agent that allowed the reduction of both $\mathrm{Ag}^{+}$-ions to silver atoms and further aggregation of silver atoms to colloids of an adequate size to give rise to a red colouring. Transmission electron microscopy was used for direct observation of silver colloids after the aggregation process, which occurred simultaneously with the ion-exchange at the selected temperature. Simple carbon replicas of the exchanged layers attacked with diluted HF for $15 \mathrm{~s}$ were prepared and studied with a Philips EM300 microscope. 

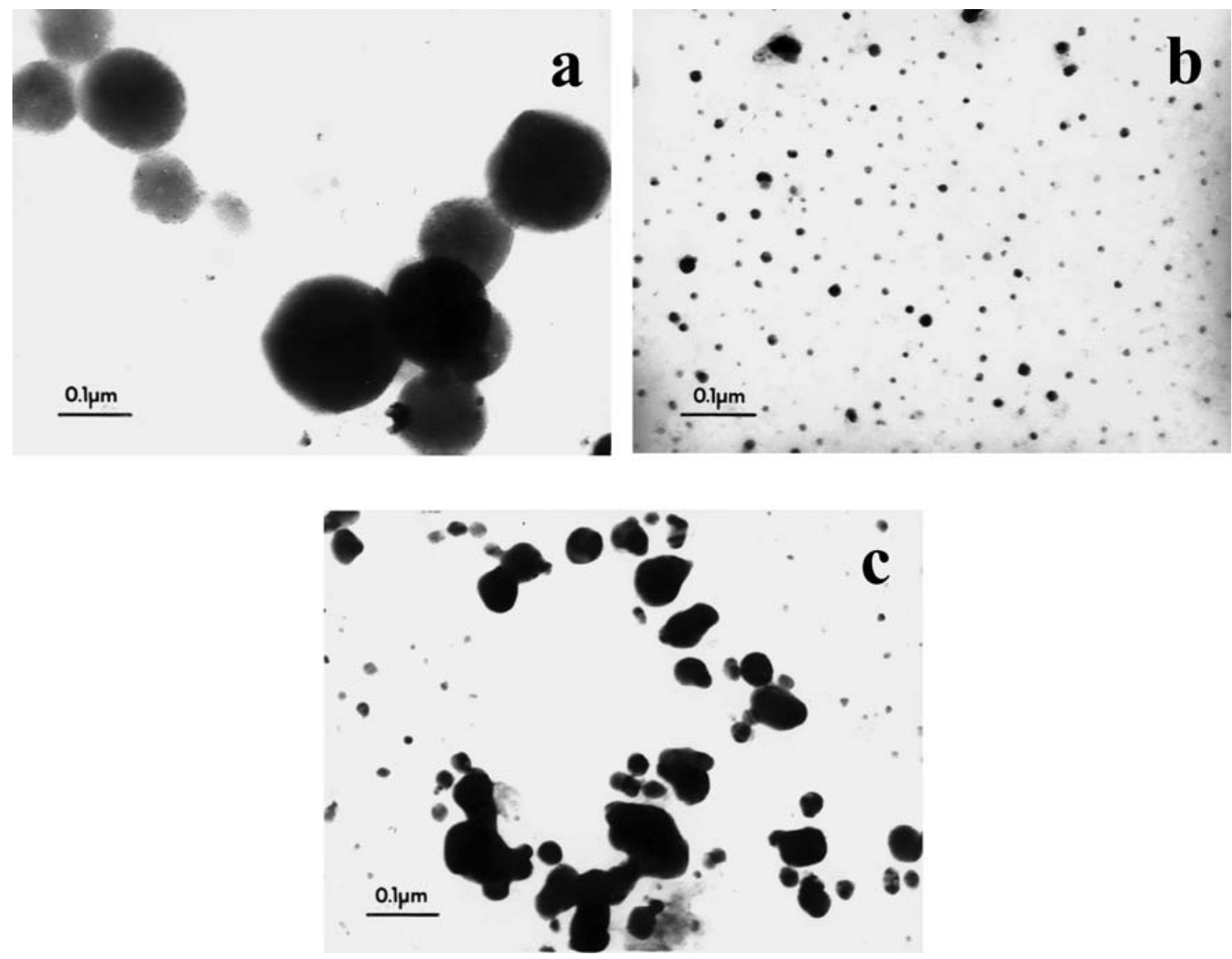

Figure 4 TEM micrographs of $1 \mathrm{wt} \%$ arsenic oxide doped samples ion-exchanged at $450^{\circ} \mathrm{C}$ for $60 \mathrm{~min}$.

Absorption and transmission spectra of glass samples were recorded with a Perkin-Elmer Lambda 19 spectrophotometer in the visible range. Colour coordinates, dominant wavelength and colour purity percentage, were calculated from the corresponding transmission spectra, according to illuminant C (CIE 1931 corresponding to the spectral distribution of medium solar light for cloudy sky).

\section{Results and discussion}

\subsection{Yellow ruby colouring on undoped lead glass}

Silver exchanged samples of undoped lead glass showed yellow colour, amber or brown. Colouring is more intense for the highest temperature and the longest time of ion-exchange. Thus, it was possible to obtain either colourless glasses for soft treatment (after $350^{\circ} \mathrm{C}$ and $30 \mathrm{~min}$ exchange) or opaque glasses for treatment under strong conditions (after $500^{\circ} \mathrm{C}$ and $60 \mathrm{~min}$ exchange).

After heat-treatment, diffusion profiles for $30 \mathrm{~min}$ ion-exchanged samples at different temperatures were recorded. As is shown in Fig. 1a-d penetration depth increased with the exchange temperature, reaching $30 \mu \mathrm{m}$ for the glass ion-exchanged at $500^{\circ} \mathrm{C}$. On the other hand, the amount of silver colloids also increased with the exchange temperature, varying from 25 counts at $350^{\circ} \mathrm{C}$ to 50 counts at $500^{\circ} \mathrm{C}$. With the aim to select the best conditions for the experimental process, $500^{\circ} \mathrm{C}$ was fixed as the exchange temperature, according to the results obtained. This temperature allowed the in- troduction of the deepest silver layer into the lead glass substrate.

\subsection{Red ruby colouring on arsenic doped lead glass}

Fig. 2a-c shows optical absorption spectra for $3 \mathrm{wt} \%$ arsenic oxide doped lead glass, ion-exchanged for different times into molten salts baths with $\mathrm{AgNO}_{3}$ contents from 1 to $4 \mathrm{~mol} \%$. Spectra were grouped according to the $\mathrm{AgNO}_{3}$ concentration in the exchange bath for several dipping times $(1,5,15$, and $30 \mathrm{~min})$. The higher the $\mathrm{AgNO}_{3}$ molar percentage in the salts bath, the more

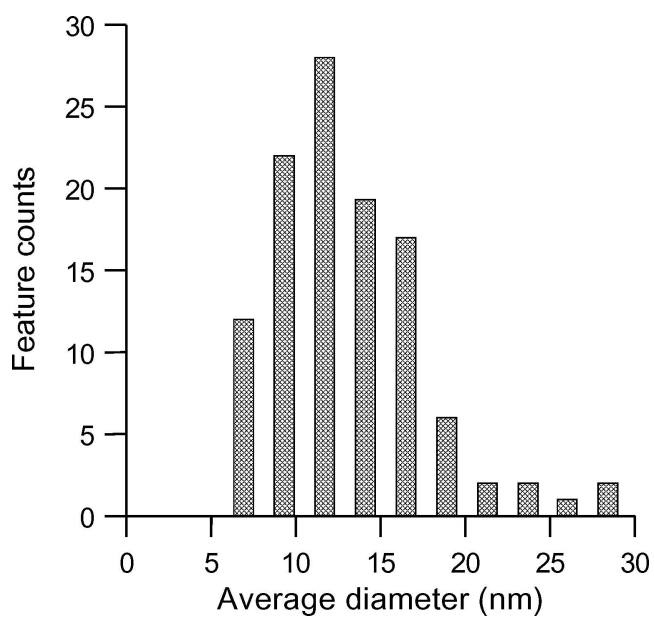

Figure 5 Particle size distribution of the smallest silver colloids of the same glass as that of Fig. 4. 


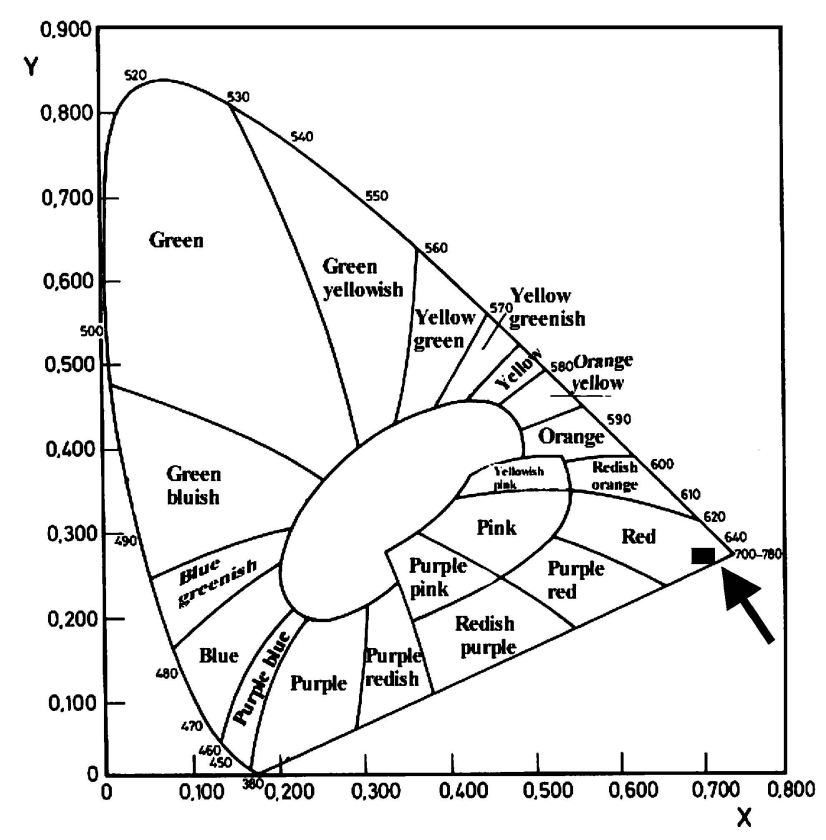

Figure 6 Chromaticity chart showing position of colour coordinates for arsenic oxide doped samples ion-exchanged with silver (red ruby colouring).

TABLE II Samples reference name and experimental conditions to obtain red ruby samples, in which colour coordinates were calculated

\begin{tabular}{llc}
\hline $\begin{array}{l}\text { Samples reference } \\
\text { name }\end{array}$ & $\begin{array}{l}\mathrm{AgNO}_{3}(\mathrm{~mol} \%) \text { in salts } \\
\text { bath }\end{array}$ & $\begin{array}{l}\text { Time (min) of } \\
\text { ion-exchange }\end{array}$ \\
\hline 1.1 & 1 & 1 \\
1.5 & 1 & 5 \\
1.15 & 1 & 15 \\
1.30 & 1 & 30 \\
2.1 & 2 & 1 \\
2.5 & 2 & 5 \\
2.15 & 2 & 15 \\
2.30 & 2 & 30 \\
4.1 & 4 & 1 \\
4.5 & 4 & 5 \\
4.15 & 4 & 15 \\
4.30 & 4 & 30 \\
\hline
\end{tabular}

intense was the absorption band obtained. The only absorption band clearly observed (maximum at $475 \mathrm{~nm}$ ) corresponded to samples exchanged for $1 \mathrm{~min}$. In the case of samples ion-exchanged for longer times, optical saturation was produced, which increased for higher $\mathrm{AgNO}_{3}$ concentrations.

In order to study the influence of the processing parameters on the optical absorption of ion-exchanged
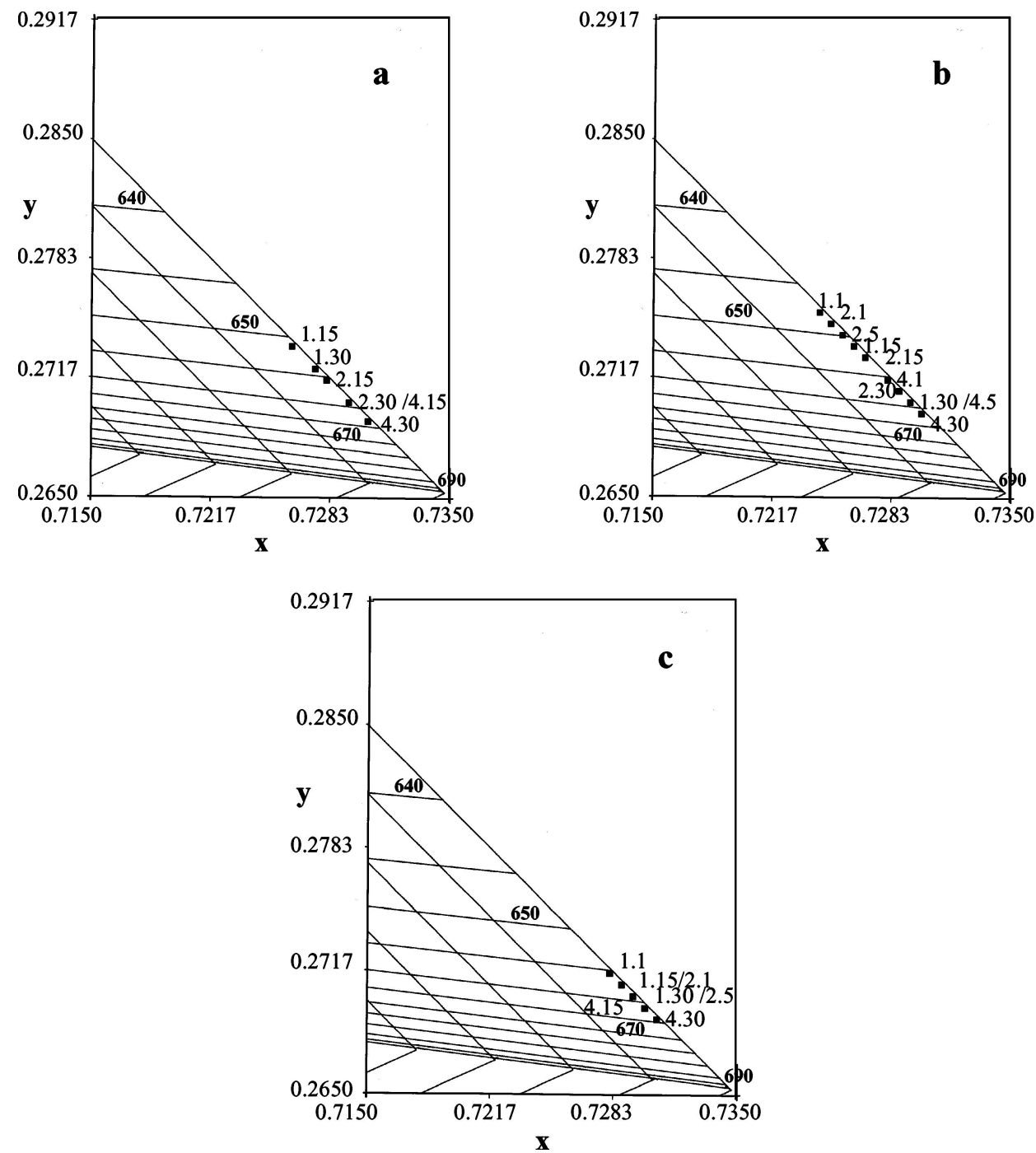

Figure 7 Enlargement of chromaticity chart area for red domain, where calculated colour coordinates are plotted. Samples doped with arsenic oxide, (a) $1 \mathrm{wt} \%$, (b) $3 \mathrm{wt} \%$ and (c) $5 \mathrm{wt} \%$. 
samples, a fixed wavelength $(630 \mathrm{~nm})$ in the corresponding spectra was selected. Fig. 3a-c summarises the absorption intensities obtained at that wavelength for 1, 2, and $4 \mathrm{~mol} \% \mathrm{AgNO}_{3}$, respectively, versus the exchange time for glasses containing 1, 3, and $5 \mathrm{wt} \%$ of arsenic oxide as reducing dopant. Samples containing the highest dopant percentages generally showed the highest optical absorption, for all the $\mathrm{AgNO}_{3}$ concentrations. On the other hand, absorbance intensities at $630 \mathrm{~nm}$ also increased with the $\mathrm{AgNO}_{3}$ percentage. The slope of the different lines in Fig. 3 are positive, except for the longest exchange times with 2 and $4 \mathrm{~mol} \%$ $\mathrm{AgNO}_{3}$ in samples doped with $5 \mathrm{wt} \%$ arsenic oxide. This could be attributed to a saturation effect during silver introduction by ion-exchange, which probably promoted formation of big aggregates whose optical absorption modified the spectral pattern.

TEM observations of samples doped with $1 \mathrm{wt} \%$ arsenic oxide and exchanged at $450^{\circ} \mathrm{C}$ for $60 \mathrm{~min}$ (salts bath containing $2 \mathrm{~mol} \% \mathrm{AgNO}_{3}$ ) demonstrated the presence of silver colloids. Micrographs of Fig. 4ac show silver particles of different size that coexist all along the sample. Particle size distribution diagram (Fig. 5) of the smallest colloids was obtained by image analysis from TEM micrographs. A bimodal distribution with small silver colloids $12 \mathrm{~nm}$ sized (Fig. 5) and large silver particles of about $100 \mathrm{~nm}$ (not showed in Fig. 5) were confirmed. Thus, particular distribution of silver particles responsible for red ruby colouring could be attributed to the aggregation degree, size and shape of silver colloids, rather than to the total concentration of silver introduced by ion-exchange. It is noteworthy that yellow ruby common glasses (soda lime silicate glasses) obtained by the same method had a single particle size distribution with silver colloids of about $5 \mathrm{~nm}$ [9].

Colour coordinates of ion-exchanged samples from arsenic oxide doped glasses were calculated according to illuminant $\mathrm{C}[11,12]$. Chromaticity chart drawn in Fig. 6 includes, on the right side edge upon the 640 $700 \mathrm{~nm}$ range, the position of colour coordinates for all the samples. That area belongs to the red colour domain with purity percentage between 98 and $100 \%$. In order to carry out an accurate study of the colour coordinates position for both set of glasses, an enlargement of that chromaticity chart area was performed in Fig. 7a-c. Table II shows the experimental conditions and the names used for the red ruby samples in which colour coordinates were calculated. Fig. 7a, related to samples doped with $1 \mathrm{wt} \%$ arsenic oxide, silver exchanged under several experimental conditions, shows dominant wavelengths in the $650-660 \mathrm{~nm}$ range with colour purities near $100 \%$. For the $3 \mathrm{wt} \%$ arsenic oxide doped set exchanged with silver (Fig. 7b), purity percentage was $100 \%$ for all samples, whereas dominant wavelength range was enlarged from 640 to $660 \mathrm{~nm}$ in the red domain. In this case, the coordinates evolution directly depends on the $\mathrm{AgNO}_{3}$ content and the exchange time. Fig. 7c shows colour coordinates position for $5 \mathrm{wt} \%$ arsenic oxide doped glasses silver ionexchanged. Dominant wavelength range was extended to $650-660 \mathrm{~nm}$ and colour purity was again near $100 \%$.

\section{Conclusions}

Yellow ruby colouring upon lead crystal glass was obtained by means of ion-exchange with silver nitrate. Colouring was more intense as the exchange temperature was raised from 350 to $500^{\circ} \mathrm{C}$, as well as for the longest exchange time tested $(60 \mathrm{~min})$. Thermal treatment during ion-exchange or after it (developing heat-treatment) favoured silver reduction and aggregation to form the colloids responsible for colouring.

Likewise, superficial red ruby colouring was obtained by silver ion-exchange of arsenic oxide doped lead glass. The dopant played as a thermoreducing agent, favouring $\mathrm{Ag}^{+}$-ions reduction to silver atoms, which aggregated to small colloids. In this case the presence of colloids of different size, as well as their shape and spatial arrangement, can account for the red ruby colour reached.

From the results obtained, a selection of the ionexchange processing parameters can be performed in order to reach a reliable and controllable process to superficial red ruby lead glass: the best dopant percentage was $3 \mathrm{wt} \%$ of $\mathrm{As}_{2} \mathrm{O}_{5}$ added to the lead glass substrate, salts bath composition $4 \mathrm{AgNO}_{3} \cdot 96 \mathrm{NaNO}_{3}(\mathrm{~mol} \%)$, exchange time in the 15 to $30 \mathrm{~min}$ range and temperature at about $500^{\circ} \mathrm{C}$.

Ruby colouring, both yellow and red, obtained by the silver ion-exchange process here investigated, fitted well with chromatic characteristics and colour purity required for decorative purposes of lead crystal glass produced by the Real Fábrica de Cristales at La Granja de San Ildefonso (Spain).

\section{References}

1. J. M. FERNÁNDEZ NAVARRO in "El vidrio" (CSIC, Madrid, 1985) p. 440.

2. R. G. NEWTON and J. R. TAYLOR, Glass Technol. 31(2) (1990) 69.

3. P. W. WANG, L. ZHANG, T. YING and W. CHENGYU, in Proceedings of the XVII International Congress on Glass, Beijing, October 1995, edited by the Organising Committee (Internal Academic Publisher, Beijing, 1995) Vol. 4, p. 53.

4. P. W. WANG, L. ZHANG, Y. TAO and CH. WANG, J.Amer. Ceram. Soc. 80(9) (1997) 2285.

5. K. J. BERG, G. BERG and F. FRÖLICH, Silikattechnik 36 (1985) 133.

6. K. J. BERG, A. BERGER and H. HOFMEISTER, J. Phys. D - Atoms, Mol. Clust. 20 (1991) 309.

7. M. A. VilleEgas, J. M. FERnÁndeZ NAVARro, S. E. PAJE and J. Llopis, Phys. Chem. Glasses 37 (1996) 248.

8. A. BERGER, K. J. BERG and H. HOFMEISTER, J. Phys D-Atoms, Molec. Clust. 20 (1991) 313.

9. S. E. PAJE, M. A. GARCÍA, J. Llopis, M. A. VILLEGAS and J. M. FERNÁNDEZ NAVARRO, Glastech. Ber. Glass Sci. Technol. 71C (1998) 440.

10. Standard UNE 43-603-79. Vidrio. Nomenclatura y terminología. Cristal. Vidrio sonoro.

11. C. R. BAMFORD, in "Colour Generation and Control in Glass" (Elsevier, Amsterdam, 1977) p. 16.

12. W. D. WRIGHT, in "The Measurement of Colour" (Adam Hilger Ltd., London, 1969).

Received 16 March 2004

and accepted 9 May 2005 